\title{
Moderate Hepatic Insufficiency
}

National Cancer Institute

\section{Source}

National Cancer Institute. Moderate Hepatic Insufficiency. NCI Thesaurus. Code

C148420.

Findings indicating moderate impairment of liver function. 